\title{
CIDADE E PORTO NA ECONOMIA DO PETRÓLEO Análise do novo terminal portuário de Macaé/RJ
}

\author{
CITY AND PORT IN THE OIL ECONOMY \\ Analysis of the New Port Terminal of Macaé / RJ
}

Resumo: 0 artigo apresenta uma análise das políticas públicas de planejamento urbano, na cidade de Macaé, relacionadas ao empreendimento portuário TEPOR, em um contexto de reestruturação logística regional das atividades ligadas à indústria do petróleo e gás. Novas demandas foram criadas nesse setor, e a cidade sente as repercussões das mudanças. Uma delas é a necessidade de ampliação das atividades portuárias como justificativa para a manutenção do sistema de desenvolvimento econômico local principal. A metodologia de pesquisa foi baseada em revisão bibliográfica, levantamento documental, sistematização das principais leis municipais que tratam do planejamento urbano e arquivos de vídeos e transcrições de audiências públicas relativas ao empreendimento portuário em análise. Enfim, diante de um contexto de descentralização das políticas públicas e da falta de um planejamento e de uma articulação política regional, verifica-se a consolidação de um cenário competitivo entre cidades pela atração de investimentos portuários, e assim, distancia-se a ideia de que cidade, porto e região se potencializem mutuamente.

Palavras-chave: Planejamento urbano. Petróleo e gás. Porto.
Abstract: The article presents an analysis of public policies for urban planning in the city of Macaé, Rio de Janeiro State, Brazil, related to the port enterprise TEPOR, in a context of regional logistics of activities related to the oil and gas industry. New demands were created in this sector and the city experiences the effects of the changes. One of them is the necessity of expanding port activities to support the main local economic development system. The research methodology was based on literature review, documentary survey, systematization of the main municipal laws dealing with urban planning and video files and transcriptions of public hearings related to the port enterprise under analysis. Finally, in a context of decentralization of public policies and lack of planning and regional political articulation, there is the consolidation of a competitive scenario between cities by attracting port investments, and thus the idea that the city, port and region are mutually enhanced.

Keywords: Urban planning.Oil and gas. Port.

Rodrigo Pyramides Pinheiro

Mestrando em Planejamento Regional e Gestão da Cidade - UCAM. Professor do Instituto Federal

Fluminense - Campus Macaé. pyramidesarquitetura@gmail.com. (22) 98131-3950

\section{Ana Paula Serpa Nogueira de Arruda}

Doutora em Sociologia Política pela UENF. Professora da Universidade Candido Mendes - Campos

serpanogueira@gmail.com. (22) 99842-0194 


\section{INTRODUÇÃO}

0 objetivo do artigo é apresentar uma análise das políticas públicas de planejamento urbano em Macaé (RJ), voltadas para a viabilização e aprovação do empreendimento portuário TEPOR, em um cenário de reestruturação logística regional das atividades ligadas à indústria do petróleo e gás bem como sua articulação em um contexto mais amplo, de capitalismo e de financeirização e competição entre cidades.

A discussão de uma proposta para a implantação de um novo terminal marítimo em Macaé tornou-se pública em meados de 2011, quando a prefeitura do município anunciou que o TEPOR seria construído, por meio de uma parceria público-privada, no bairro de São José do Barreto, área urbana localizada no litoral da Região Norte da cidade.
A localização do terreno é estratégica, uma vez que está cerca de $5 \mathrm{~km}$ do aeroporto de Macaé, a $4 \mathrm{~km}$ do Terminal de Cabiúnas da Petrobras (TECAB) - unidade de processamento de gás natural e a $10 \mathrm{~km}$ do acesso principal à cidade pela BR-101 (RIMA TEPOR, 2014). De forma geral, a região onde se propõe a construção do TEPOR possui uma ocupação heterogênea, com adensamento consideravelmente recente e majoritariamente ocupada por uso residencial para população de baixo poder aquisitivo.

\section{Figura 1 - Localização do TEPOR no bairro São José do Barreto.}

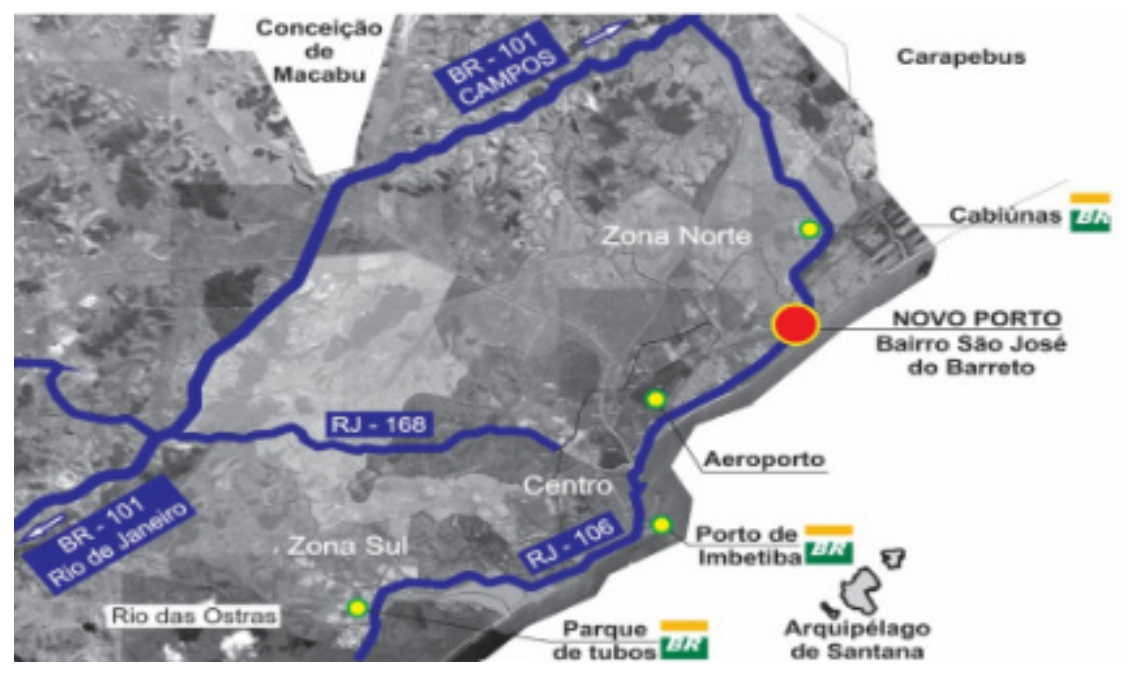

Fonte: Autoria própria (2020), sobre aerofotogrametria de Macaé

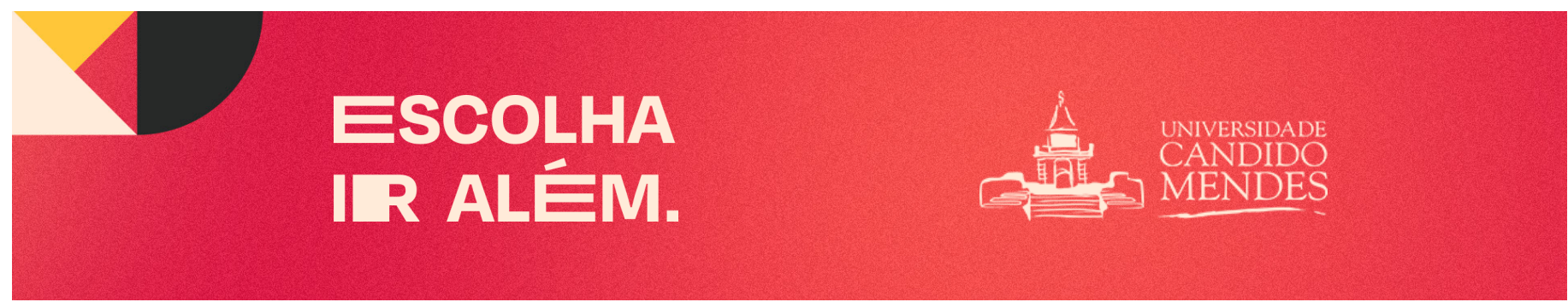


Inicialmente, a construção do novo porto foi justificada pela limitação da capacidade de operação do porto de Imbetiba. Porém, posteriormente, uma nova proposta do projeto foi apresentada, segundo o grupo empreendedor, devido às novas demandas e logísticas da recente política econômica do petróleo.

Assim, houve uma significativa reformulação e ampliação das atividades apresentadas anteriormente, o que nos convida a refletir e a buscar compreender quais fatores foram determinantes para que esta reestruturação ocorresse e, ainda, como as políticas públicas de planejamento urbano local têm interagido e participado deste processo, uma vez que o empreendimento portuário apresentado potencializa uma significativa transformação na dinâmica urbana de Macaé e região.

Contudo, primeiramente, tornou-se necessário compreender o contexto mais amplo em que essas transformações estão inseridas, ou seja, como o equipamento portuário e a indústria do petróleo têm se moldado ao contexto econômico global atual para, em seguida, entender como Macaé, cidade portuária e industrial petrolífera, se insere, interage e é influenciada pelos imperativos do sistema econômico mundial e quais desdobramentos poderão se configurar no tecido urbano da cidade, notadamente através de suas políticas públicas de planejamento urbano.

0 percurso metodológico adotado na pesquisa, em um primeiro momento, baseou-se em revisão de literatura. A busca de repertório teórico acerca do tema central e do projeto específico do TEPOR descortinou uma rede complexa de temáticas correlatas que foram apresentadas do contexto global para o local e dos temas de abrangência generalista para especialista.

Neste sentido, o estudo baseou-se no entendimento de que o planejamento e a gestão das cidades na sociedade contemporânea são pautados pela lógica e racionalidade do atual estágio de acumulação capitalista, articulados em uma escala global, como apresentado por Castells (1983). 0 autor esclarece que o processo de urbanização torna-se, então, a expressão, em nível do espaço, desta dinâmica social e exprime, nas suas formas e nos seus ritmos, a articulação concreta das relações econômicas e políticas.

Os desafios das cidades portuárias frente a esta realidade são imensos considerando que a economia mundial atual está atrelada à abertura e liberação do comércio e da produção globalizada, facilitada pelos avanços tecnológicos. Isso requer delas um maior envolvimento em atividades de planejamento, haja vista o papel preponderante dos portos nesse contexto logístico de circulação internacional de mercadorias e como agentes de promoção de desenvolvimento para as localidades onde se inserem.

Como ressaltam Monié e Vidal (2006), a reorganização dos espaços produtivos e o surgimento de dinâmicas comerciais específicas, caracterizadas pela crescente integração das esferas da produção, do consumo e da circulação em todas as escalas geográficas, incluíram um conjunto de mudanças na estrutura mundial dos portos.

Assim, frente aos novos padrões de desenvolvimento e determinismos tecnológicos, Monié e Vasconcelos (2012) classificam as cidades portuárias da atualidade em duas tipologias: a primeira, como territórios de circulação; a segunda, e/ou territórios produtivos. Ou seja, no contexto urbano, o porto é entendido e estruturado como um simples ponto de transbordo e nó de trânsito para o mercado de circulação global, consolidando uma dinâmica endógena e de distanciamento e autonomia para com a cidade onde se insere, caracterizando a primeira tipologia; e/ou é entendido como um instrumento a serviço do desenvolvimento local e/ou regional, no caso da segunda, por meio de uma aproximação entre o porto e a cidade (MONIÉ e VIDAL, 2006), agregando a fixação local de valor dos fluxos de cargas globais.

Porém, como ressaltam Monié e Vidal (2006), no Brasil, a ausência de uma política portuária nacional conferiu às iniciativas federal ou locais um caráter fragmentado, ficando, portanto, a definição de políticas públicas urbanas das relações porto-cidade mais uma vez da escala global para a local. Isto posto, para a implantação da maioria dos novos equipamentos portuários no território, promove-se uma fraca interação entre o porto e a cidade na lógica atual, onde cresceu o distanciamento do porto em relação ao entorno no qual se insere.

Nesse sentido, torna-se importante analisar como está sendo planejada a relação do equipamento portuário e a cidade macaense, uma vez que este será construído em uma área urbana do município, onde a extensão de litoral já possui ocupação urbana, salvo trechos de fragmentos remanescentes de vegetação de restinga. 


\section{Planejamento urbano, petróleo e cidades portuárias: do global para o local}

As cidades, na atualidade, são reflexo e produto das novas dinâmicas de reprodução do capital. Como salienta Arantes (2000, p. 28), "a globalização faz com que as cidades sejam geridas não como negócio, mas para o negócio". Nessa perspectiva, 0 tradicional planejamento urbano, fundamentado na técnica e na centralidade do Estado, passa a incorporar o viés político, sendo concebido tendo em vista o ambiente competitivo internacional em que a cidade está inserida. As dinâmicas decisórias, nesse contexto, demandam novas articulações que envolvem diferentes atores.

A instauração do Capitalismo Mundial Integrado é o momento caracterizado por Rolnik (1994) pela instauração de um processo de desmonte progressivo das barreiras nacionais por meio do mecanismo da mídia e das tecnologias de comunicação, da transnacionalização dos capitais e da mundialização dos mercados. Tende-se, por conseguinte, a um enfraquecimento progressivo dos estados nacionais e à derrocada das políticas desenvolvimentistas protecionistas. Portanto, há uma redefinição do papel do Estado, no sentido de diminuir seu protagonismo e sua descentralização política, delegando mais competências aos governos locais.

E assim a cidade assume a competência da organização social e política local, legitimada pela Constituição de 1988. Nesse sentido, segundo Castells e Borja (1996), governos locais assumem atribuições para atrair novos investimentos em um cenário de escassez de recursos e de acirramento da competição entre cidades. Houve, portanto, um redesenho importante na atribuição do governo local, que além de responsável pelo gerenciamento de infraestrutura, bens e serviços urbanos, assume também 0 papel de promotor da diversificação e modernização de negócios em seu território, tornando-se um empreendedor econômico.

A maneira como esse processo de dinâmica global afeta a governabilidade e o espaço das cidades tem sido bastante debatido em âmbito nacional. Santos (2000) esclarece que a globalização é, de certa forma, o ápice do processo de internacionalização do mundo capitalista. É também o resultado das ações que asseguram a emergência de um mercado dito global.

0 autor expõe uma interpretação multidisciplinar do mundo contemporâneo, ressaltando o papel perverso da informação e do dinheiro, que, paraSantos (2000), são apresentados como os pilares de uma situação em que o progresso técnico é aproveitado por um pequeno número de atores globais em seu benefício exclusivo. 0 resultado é 0 aprofundamento da competitividade, a produção de novos totalitarismos, a confusão dos espíritos e o empobrecimento crescente das massas, enquanto os Estados tornam-se incapazes de regular a vida coletiva.
$\mathrm{Na}$ perspectiva do espaço urbano, identificam-se os desdobramentos que decorrem do impacto da globalização e da ação do Estado, de reprodução da lógica do capital na urbanização das cidades, apontadas por Lefebvre (2001) como 0 aprofundamento das desigualdades socioespaciais. Com efeito, as políticas públicas urbanas estão sendo formatadas para atender às exigências estruturais decorrentes da globalização, o que ocorre em detrimento daquela parcela da cidade que não conta com políticas públicas provedoras de infraestrutura básica para sua sobrevivência.

Com a redefinição do papel do Estado nacional, no sentido de diminuir seu tamanho e protagonismo, houve, no Brasil, com a Constituição de 1988, a descentralização política, no sentido de delegar mais competências aos governos locais. Neste momento de democratização da gestão, os governos municipais também foram encarregados de estabelecer espaços de interlocução com a sociedade no processo de elaboração das suas políticas. Assim, a cidade passou a assumir o protagonismo econômico-político, ou seja, a formular estratégias econômico-político-territoriais para o futuro da cidade.

Nessa perspectiva, nota-se que o governo municipal macaense tem assimilado essas tendências de reorientação do planejamento urbano, uma vez que tem se empenhado de forma ativa para a viabilização de grandes empreendimentos em seu território.

No caso específico do empreendimento portuário, a cidade consolidou-se ao longo de décadas como base de apoio territorial à exploração e extração de óleo e gás da Bacia de Campos, principalmente devido à presença do porto de Imbetiba. Inúmeros investimentos direcionados ao setor foram feitos no município. Assim, atualmente, grande parte da receita municipal é proveniente de royalties, participações especiais, e Impostos sobre Serviços (ISS) das empresas vinculadas à indústria petrolífera.

Porém, em 2014, a Bacia de Campos perdeu protagonismo na política estratégica da Petrobras bem como Macaé. Nader (2019) descreve dois movimentos que contribuíram: o primeiro, mais amplo, a partir de investimentos em novas fronteiras exploratórias fora da Bacia de Campos, com o direcionamento de investimentos com prioridade voltada para a produção no pré-sal da Bacia de Santos; o segundo movimento, tem se configurado no âmbito regional, concretizando um movimento interno na própria bacia,denominado pelo autor como "transbordamento" da dinâmica econômica dessa indústria para além das fronteiras macaenses em direção aos outros municípios, como Rio das Ostras e Campos dos Goytacazes.

Além desse redesenho operacional e logístico que vem ocorrendo na cadeia do petróleo e gás em âmbito regional, também contribuíram para a interrupção do ciclo de prosperidade em Macaé fatores vivenciado pelo setor de petróleo e gás, descritos a seguir: queda do preço internacional do barril de petróleo, 
que fez com que a indústria mundial do segmento retraísse os investimentos; impactos da Operação Lava Jato, uma vez que a Petrobras divulgou um bloqueio cautelar para um conjunto de empresas prestadoras de serviços; crise financeira e de credibilidade vivenciada pela Petrobras, que diminuiu seus investimentos; crises política e econômica do Brasil, que afetaram as perspectivas de investimentos na economia brasileira somadas à falta de leilões de novas áreas para exploração de petróleo, gerando forte contração de investimentos no setor; e queda na arrecadação dos royalties provenientes da produção petrolífera (NADER, 2019).

Nesse sentido, apolítica estratégica da Petrobras prevista para a Bacia de Campos é trabalhar com o desinvestimento em áreas onde a empresa considera que a produção não apresenta condições econômicas para operar. A proposta, então, é a de trabalhar com descomissionamento de alguns campos e de venda de alguns ativos, para empresas que tenham interesse na revitalização de campos maduros.

Esse processo de desativação de um campo pode gerar receita e oportunidade para um segmento particular da indústria, especificamente para a análise deste trabalho, em que os complexos portuários se fazem essenciais, uma vez que as instalações devem ser desmontadas e levadas de volta ao continente para receberem a destinação adequada, como reuso e reciclagem. Porém, observa-se que esses investimentos em revitalização de campos e descomissionamentos apenas acontecerão por mais um curto período, já que a finalização da produção nos mesmos parece inevitável.

Nesse sentido, o município de Macaé tem buscado no gás natural uma alternativa estratégica de planejamento em médio prazo. Isso se justifica pela crescente participação do gás natural na matriz energética brasileira, como "combustível de transição" para uma economia de baixo carbono e, assim, aproveitar estrategicamente décadas de investimentos realizados na área continental que abrange a Bacia de Campos, como a rede de dutos que viabiliza a conexão com as unidades de refino localizadas próximas aos centros consumidores.

0 município de Macaé também se transformou no maior polo de processamento de gás natural do País quando, no início de 2016, a Unidade de Processamento de Gás Natural de Cabiúnas (UPGN - Cabiúnas) passou a receber gás natural do pré-sal vindo da Bacia de Santos, através do ramal de gasodutos da Rota 2, para ser processado. Assim, segundo Pessanha (2017), a UPGN - Cabiúnas tornou-se, junto com a malha ramificada de gasodutos, o principal hub de distribuição de gás natural do circuito espacial do petróleo do Rio de Janeiro.

Com o processamento do gás natural na cidade, o setor de petróleo tem-se ampliado no território de Macaé, a exemplo da construção de usinas termelétricas como a Usina Termelétrica Mario Lago (UTE-Mario Lago), da Petrobras e a Termelétrica
EDF Norte Fluminense, do grupo Electricité de France. Dessa forma, a cidade vai se orientando em outras atividades ligadas à cadeia do petróleo, que não exclusivamente como base de apoio e gestão da exploração e produção na Bacia de Campos.

Isso posto, o governo municipal tem investido, principalmente, na forma de incentivos fiscais, para garantir a permanência de empresas já instaladas, e na atração de investimentos privados que ajudem a qualificar Macaé como um local atrativo para novas empresas. O TEPOR, nesse contexto, emerge para o poder público local como a possibilidade da retomada do crescimento econômico da cidade.

A mudança do escopo do projeto do TEPOR - de um porto apenas para apoio operacional e de manutenção offshore, para um complexo portuário industrial especializado em petróleo e gás -, indica que os investidores do empreendimento buscaram se alinhar às futuras possibilidades previstas pelo setor para a região bem como às intenções do governo municipal para a cidade, onde procura redescobrir uma posição competitiva no redesenho em curso do circuito espacial do petróleo e gás na região.

Porém, enquanto o novo porto de Macaé ainda está em projeto e processo de licenciamento ambiental, o Complexo Portuário do Açu, localizado a aproximadamente 100 km da cidade, já é uma realidade. 0 Porto do Açu apresenta vantagens operacionais quanto ao fato de estar junto à Bacia de Campos e relativamente equidistante das importantes bacias do Espírito Santo e de Santos.

Assim, o "transbordamento" da dinâmica econômica da indústria do petróleo e gás para além das fronteiras macaenses em direção ao Açu, conforme relatado por Nader (2019) efetivou-se.

Essa proximidade entre os dois portos para a indústria do petróleo pode se tornar confortável, uma vez que as duas estruturas, objetivando atrair os investimentos, em um efeito de concorrência, alinhada às perspectivas neoliberais, acabam por ofertar serviços e instalações de maior qualidade com custos mais vantajosos. De outro lado, diante desse possível cenário competitivo, os governos municipais tendem a assumir uma postura ativa para a atração destes investimentos, cedendo áreas, alterando legislações e oferecendo, também, incentivos fiscais. Com isso, a lógica do capital se reproduz no território, e a mercantilização das cidades se efetiva, reflexo de uma política de planejamento urbano de cunho localista e desintegrada da perspectiva regional.

\section{Um novo porto para Macaé}

A área inicialmente definida para o empreendimento possuía $60 \mathrm{mil} \mathrm{m}^{2} \mathrm{e}$ havia sido doada pela prefeitura, pelo Projeto de Lei n 027/2011 (BARBOZA e BRUST, 2011, in www.macae.rj.gov. br). Inicialmente, foi firmada uma parceria entre a prefeitura e o Grupo Queiroz Galvão. Posteriormente, esse grupo adquiriu os 
direitos do empreendimento e se associou a mais dois grupos, Meira Lins e AlbarLogistics. 0 novo grupo de empreendedores adquiriu novos terrenos, ampliando a área terrestre do porto para $400.000 \mathrm{~m}^{2}$.

Assim, o terminal portuário passou a ser de uso privado, com licença prévia - processo n. ${ }^{0}$ 007/002.1325/2013 - solicitada junto ao órgão licenciador Instituto Estadual do Ambiente (INEA) e obtida em junho de 2016 (disponível em http://rj.rap.gov.br/) após a realização de duas audiências públicas. A primeira delas ocorreu em 15 de janeiro de 2014, no Centro de Integração de Ensino Público (CIEP) Leonel de Moura Brizola; e a segunda, em 16 de julho de 2014, no Centro de Convenções Jornalista Roberto Marinho, ambas na cidade de Macaé (RJ).

Esta primeira proposta do TEPOR se tratava de um terminal logístico com o objetivo de atender exclusivamente às demandas de suprimentos (movimentação de cargas e apoio logístico da cadeia de petróleo e gás), das Bacias de Campos Meio e Sul, e Bacia de Santos Norte, uma vez que, com a descoberta do présal, havia uma previsão de aumento considerável na produção e, consequentemente um crescimento do tráfego e da quantidade de embarcações de apoio logístico às plataformas offshore (fora da costa). Isso baseado na justificativa de que o porto de Imbetiba que, no período, prestava este serviço, encontrava-se saturado (RIMA TEPOR, 2014). 


\section{Figura 2 - Mapa com a implantação da primeira proposta para o novo porto de Macaé}

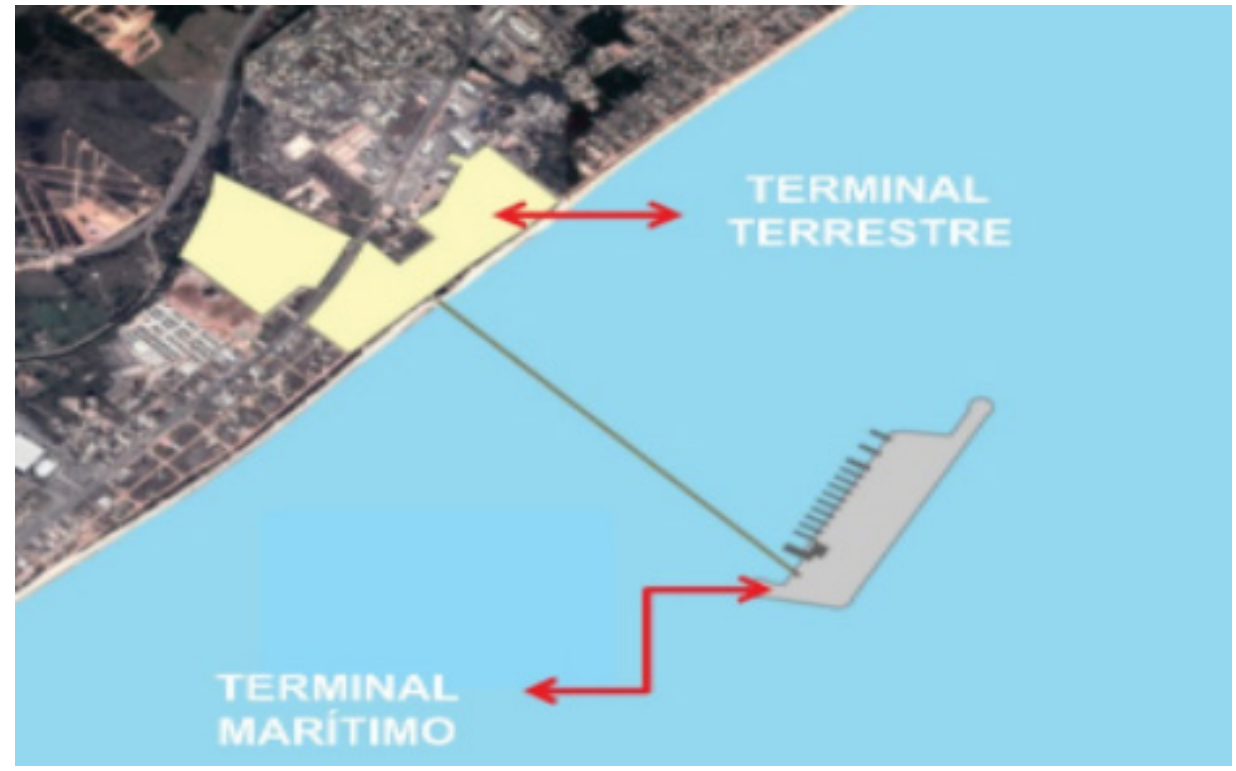

Fonte: RIMA TEPOR, 2014. Grifos do autor, 2020.

Em 2016, o empreendimento TEPOR passou a ser conduzido exclusivamente pelo Grupo EBTE Engenharia, dado que este adquiriu, da Queiroz Galvão, os direitos sobre as obras e a operação do porto (clickmacae. com.br, 2018). Apesar da obtenção da licença prévia relativa a essa primeira proposta junto aos órgãos ambientais, o então grupo, atual responsável pelo empreendimento, divulgou, em 2018, uma considerável alteração do projeto proposto inicialmente.

Assim, houve uma substituição do projeto anterior por uma proposta mais ampla e diversificada, e uma nova etapa de análise se iniciou para a aprovação da modificação do projeto do terminal, passando a se caracterizar, dessa forma, como um terminal portuário altamente especializado.

Cabe salientar que essa alteração do projeto é contemporânea às modificações do marco regulatório de regime de concessão e do contrato de partilha de produção no pré-sal, com o fim da regra de operação única, que acaba com a obrigatoriedade de a Petrobras possuir participação mínima de $30 \%$ em todos os campos do pré-sal. Com isso, em 2017, seis novos contratos de partilha de produção foram assinados. Segundo Pinto Junior (2018), três operados pela Petrobras, dois pela Shell e um pela Statoil.

Com a introdução de petrolíferas estrangeiras no processo de exploração e produção e com a redução nos percentuais de equipamentos e serviços produzidos no País - exigidos em licitações de exploração de petróleo e gás -, diminuindo a exigência do conteúdo local, há também uma facilitação da entrada de mais empresas estrangeiras fornecedoras de serviços, inclusive por meio de isenções para importação de máquinas e equipamentos.

Sendo assim, frente às novas demandas e logísticas da recente política econômica do petróleo, a nova proposta de projeto do TEPOR, reformula e amplia as atividades apresentadas anteriormente, uma vez que não mais apenas a Petrobras e suas subsidiárias se enquadram no perfil de possíveis clientes para o porto, como explicitado na primeira proposta.

Nesse sentido, houve alterações no número de berços, terminais, calados e retroáreas, além da incorporação de todo um sistema dutoviário não contemplado no projeto original.

De acordo com o Relatório de Impacto Ambiental do empreendimento (RIMA, 2018), o TEPOR assume status de complexo portuário, sendo constituído de instalações em áreas marítimas e terrestres, onde serão desenvolvidas atividades industriais, de logística, de armazenamento e distribuição de produtos para o setor de óleo e gás.

A área offshore será composta de dois terminais e a área terrestre, onshore, composta por três retroáreas. A Figura 3 apresenta a implantação geral da proposta desse projeto. 
Figura 3 - Mapa com a implantação da atual proposta para o novo porto de Macaé.

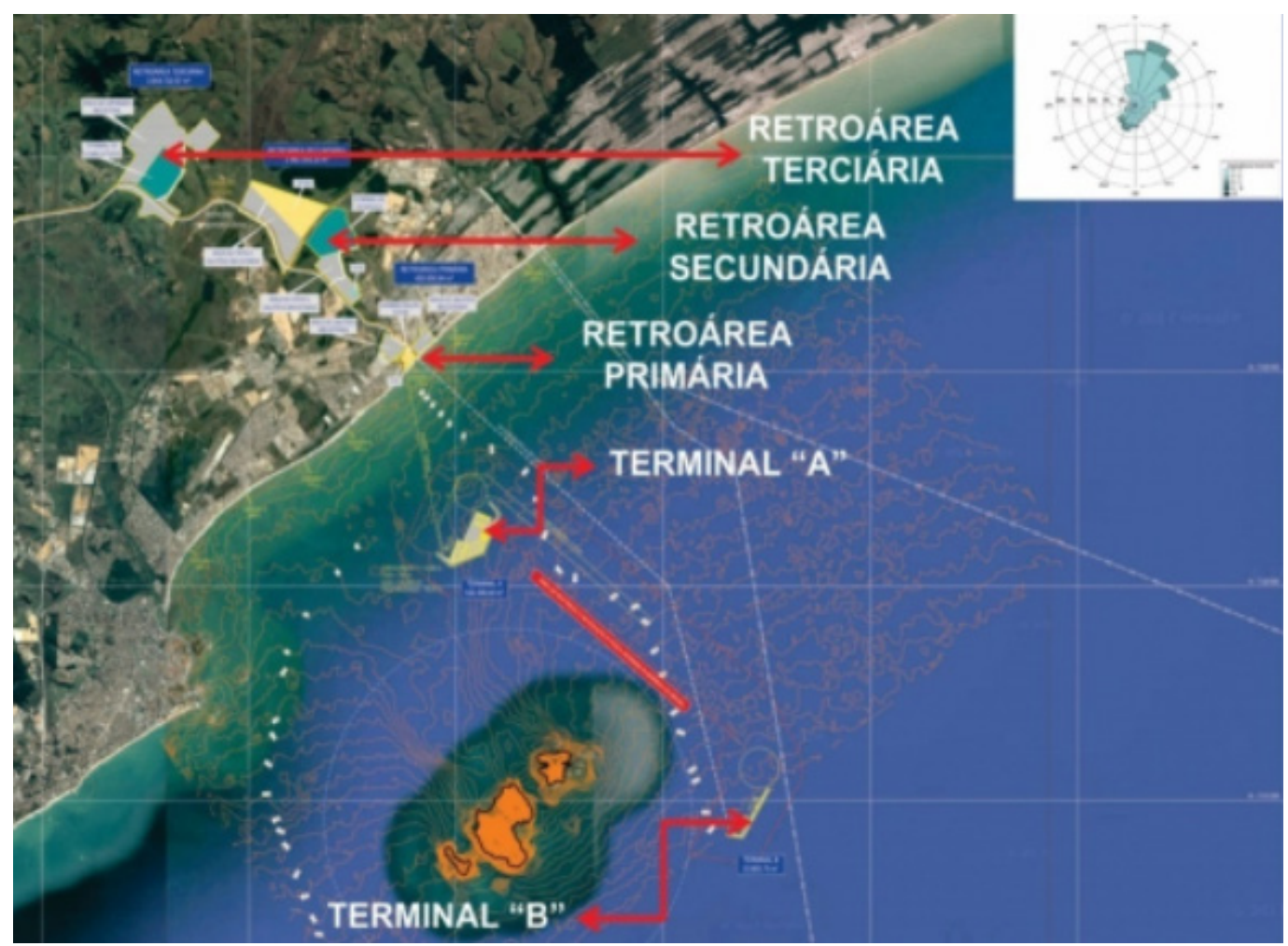

ESCOLHA IR ALËM.

Vestibular 2021

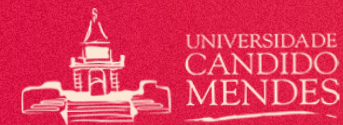

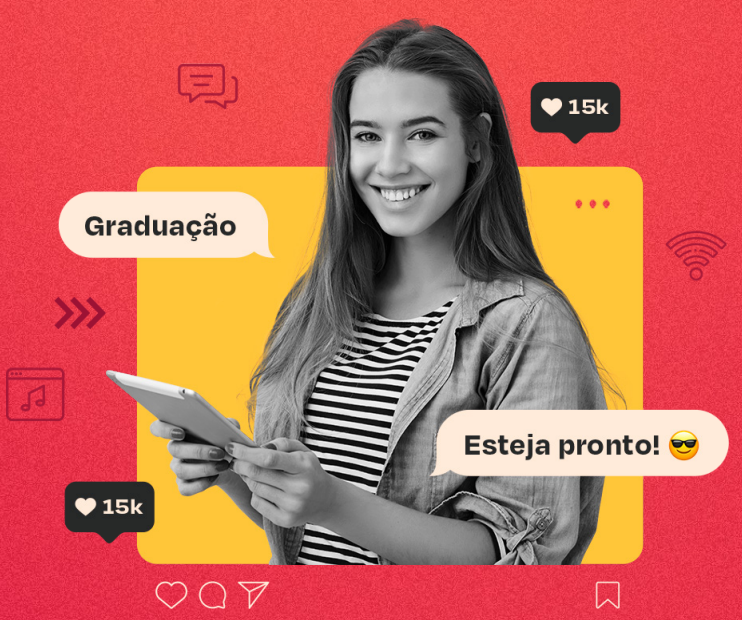


Tabela 1: Diferenças entre as propostas inicial e atual do TEPOR.

\begin{tabular}{|c|c|c|}
\hline ITEM & PROPOSTA INICIAL & PROJETO ATUAL \\
\hline $\begin{array}{ll}\text { Programa } & \text { de } \\
\text { atividades } & \end{array}$ & $\begin{array}{l}\text { Apoio de suprimentos e } \\
\text { manutenção para as } \\
\text { plataformas. }\end{array}$ & $\begin{array}{l}\text { Apoio de suprimentos e manutenção para as } \\
\text { plataformas; } \\
\text { Movimentação (importação e exportação) de } \\
\text { granéis liquidos e gasosos e cargas gerais; } \\
\text { Atracação de plataformas ou sondas para } \\
\text { manutenção ou descomissionamentos; } \\
\text { Terminal de regaseificação, para a conversão } \\
\text { de gás natural liquefeito em gás natural; } \\
\text { Sistema de resfriamento, que realizará a } \\
\text { conversão, em estado liquido, de gases } \\
\text { provenientes da Unidade de Processamento de } \\
\text { Gás Natural; } \\
\text { Unidade de óleos combustiveis para } \\
\text { recebimento de diesel maritimo e óleo } \\
\text { combustivel; } \\
\text { Terminal de descarregamento e carregamento } \\
\text { de petróleo mar-terra; } \\
\text { Processamento de gás natural em produtos } \\
\text { derivados; } \\
\text { Terminal de tancagem de combustiveis; } \\
\text { Área de expansão industrial. }\end{array}$ \\
\hline Área onshore & $400.000,00 \mathrm{~m}^{2}$ & $6.042 .682,83 \mathrm{~m}^{2}$ \\
\hline Área offshore & 1terminal $=92.400,00 \mathrm{~m}^{2}$ & 2 terminais $=586.162,00 \mathrm{~m}^{2}$ \\
\hline Ponte de acesso & $1.680,00 \mathrm{~m}$ & $4.200,00 \mathrm{~m}$ \\
\hline Berços & 15 & Terminal A: 10; Terminal B: 2 \\
\hline Calado & $10 \mathrm{~m}$ & TA: $16 \mathrm{~m} ;$ TB: $27 \mathrm{~m}$ (profundidade natural) \\
\hline $\begin{array}{l}\text { Espigões na } \\
\text { costa macaense }\end{array}$ & 0 & 7 \\
\hline $\begin{array}{l}\text { Dutos de ligação } \\
\text { off-onshore }\end{array}$ & 0 & 14 linhas \\
\hline
\end{tabular}


A análise das alterações da proposta do empreendimento reflete a sua adequação frente à reestruturação logística regional das atividades ligadas à indústria do petróleo e gás. Nesse sentido, nos convida a refletir sobre as políticas públicas de planejamento urbano local para a viabilização e aprovação do TEPOR, uma vez que o empreendimento portuário apresentado assumirá papel preponderante de transformação na dinâmica urbana de Macaé e região.

\section{Processo de licenciamento e aprovação do projeto TEPOR}

Cenários de crises, incluindo as do setor petrolífero mundial, e as consequentes perspectivas de recessão, principalmente em países periféricos, acabaram por fomentar que as propostas políticas neoliberais ganhassem ainda mais espaço nas administrações públicas, inclusive nas municipais, repercutindo também nas políticas públicas de planejamento urbano. Assim, os gestores passaram de agentes reguladores a promotores do desenvolvimento local.

A análise do processo de aprovação do TEPOR em Macaé contribui para demonstrar o alinhamento do poder público municipal a esse modelo de gestão. 0 discurso de crise como justificativa da ação do estado reproduzindo a lógica do capital ainda não foi superado. Além de benefícios e incentivos fiscais para a atração ou permanência de empresas no município, através da Lei Complementar Municipal 247/2015, que reduziu as alíquotas de contribuição de Imposto sobre Serviços (ISS) e Imposto Predial e Territorial Urbano (IPTU) para as grandes companhias, o processo de viabilização e aprovação do empreendimento incorpora questões relativas às mudanças nas legislações urbanas e ambientais, buscando também envolver a população para a aceitação e defesa da proposta, justificada como indispensável para o reaquecimento do setor e para a geração de empregos.

Alinhado a essa lógica, apesar do discurso de necessidade de se diversificar a base da economia macaense, o governo municipal continua a pautar suas ações para o contínuo fomento da cadeia do petróleo e gás. 0 avanço do pré-sal e o grande volume de gás associado vêm sendo vislumbrados como uma oportunidade de incrementar a base industrial de Macaé, que possui uma das maiores unidades de processamento de gás natural do País.

A mudança no marco regulatório de regime de concessão e no contrato de partilha de produção no pré-sal, com o fım da regra da obrigatoriedade de a Petrobras possuir participação mínima de 30\% em todos os campos, permitindo a inserção de grandes empresas globais do setor de óleo e gás, coloca a participação da cidade de forma ainda mais efetiva em um mercado mundial altamente competitivo. Para acessar o mercado global torna-se necessário prover a cidade de equipamentos e infraestrutura que acompanhem as tendências e exigências globais.

Foi diante de um contexto de crise econômica e concorrência, principalmente com o Porto do Açu, que o projeto do TEPOR angariou apoio popular, sendo justificado como importante empreendimento que contribuiria para que "... o município se consolide no cenário nacional,

MEST RA D 0

PESQUISA OPERACIONAL E INTELIGÊNCIA COMPUTACIONAL LINHA DE PESQUISA EM SAÚDE
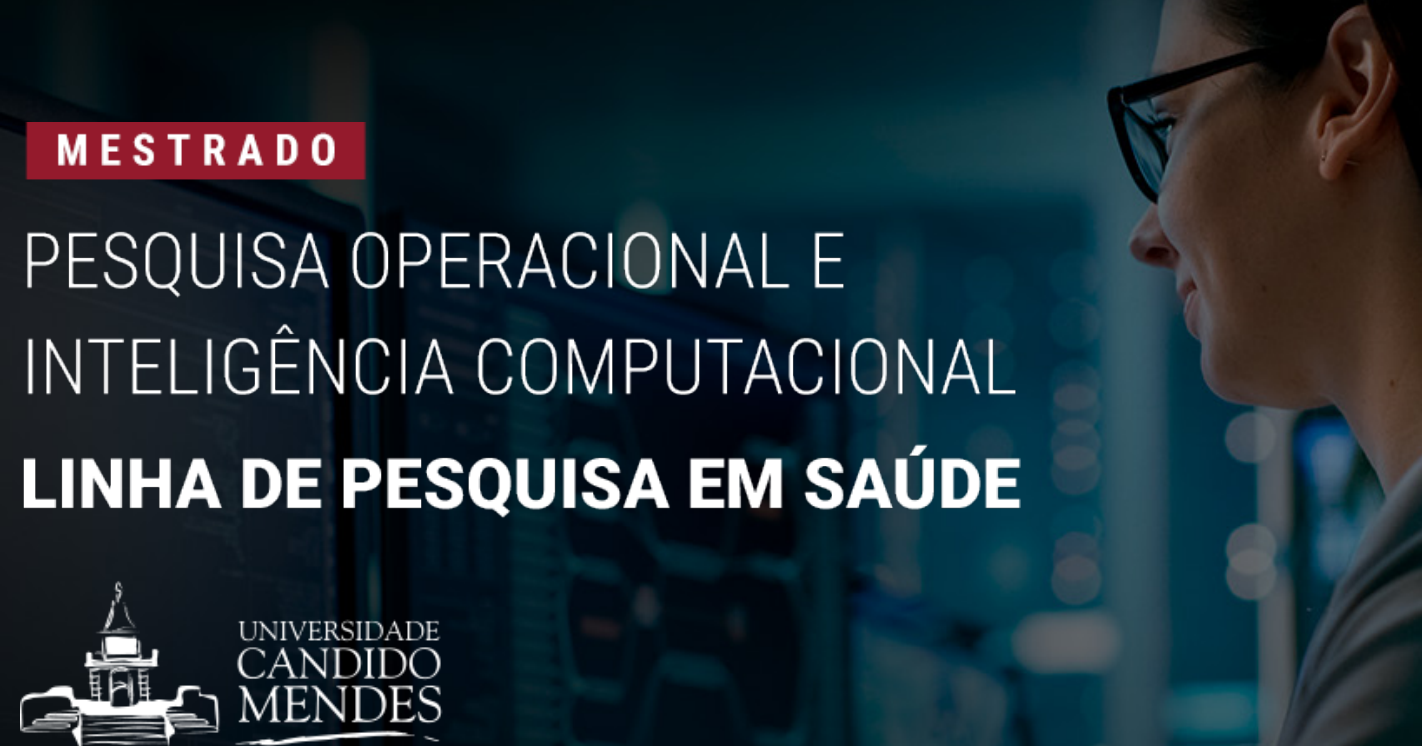

-

\section{I.}


relacionado às atividades de navegação e logística, como um polo de atração de investimentos e evitando que essa demanda se direcione para outros municípios e regiões do país..." (RIMA TEPOR, 2014:47).

Porém, com o advento das novas oportunidades no mercado do gás natural e a presença da UPGN de Cabiúnas em Macaé - conectada a uma rede de dutos importante para o País -, o projeto do TEPOR modifica-se e assume um protagonismo ainda maior na cidade como investimento promissor ao fortalecimento da economia local. Dessa forma, o governo municipal se empenha ainda mais em defender e viabilizar o empreendimento, uma vez que este também contempla e incentiva a construção de outras indústrias como as termelétricas e empresas petroquímicas em suas retroáreas.

Serão apresentadas, de forma sucinta, as discussões relacionadas ao processo de licenciamento e aprovação do empreendimento TEPOR, principalmente nas audiências públicas relacionadas ao projeto, com enfoque na postura assumida pelos gestores municipais.

Durante o processo de apresentação das três audiências públicas do empreendimento, tem-se a percepção de que a participação de pesquisadores de instituições regionais, como da Universidade Federal do Rio de Janeiro, Universidade Federal Fluminense, Instituto Federal Fluminense e representantes locais de órgãos ambientais, questionadores de aspectos técnicos da proposta, arrefeceu mesmo com a ampliação significativa da área do projeto e dos possíveis impactos ambientais.

A ativa participação de pesquisadores nas duas primeiras audiências não se efetivou na terceira, possivelmente, por terem sido hostilizados, principalmente durante a segunda audiência. Assim, na audiência relativa à modificação do projeto, não houve manifestação oral de pesquisadores, evitando, dessa maneira, debates diretos, como havia ocorrido nas anteriores. Entretanto, pesquisadores manifestaram-se. encaminhando ao INEA um relatório técnico com apontamentos e recomendações quanto aos riscos associados ao empreendimento.

Durante o processo de licenciamento do empreendimento, foram criados movimentos populares em apoio ao projeto, atuantes na segunda e terceira audiências, paralelamente ao movimento contrário, denominado "Xô, Porto!", que esteve presente desde a primeira audiência pública. Estes grupos promoveram inúmeras ações de divulgação do TEPOR e cobraram agilidade nos processos de licenciamento e de mudanças de leis como a do zoneamento urbano, entre outros, contribuindo para a construção e consolidação do apoio popular ao empreendimento, cuja licença prévia foi emitida em novembro de 2019.

Também contribuiu para facilitar o processo de licenciamento, a publicação da declaração do TEPOR como de "Interesse Público", que acabou por institucionalizar a flexibilização de leis. Nesse sentido, a faixa litorânea do terreno para a sua futura instalação - que possui um remanescente de área de restinga, sendo classificado como área de preservação permanente (APP) segundo o Código Florestal (art. $2^{\circ}$ ) - que não seria passível de ocupação, passou a ser possível, desde que se faça compensação ambiental.

Outra modificação importante foi a alteração da APA do Arquipélago de Santana. A Prefeitura Municipal de Macaé, por meio da Lei Ordinária n. ${ }^{0} 4.349$ de 2017, reduziu o raio de dezesseis quilômetros da área de proteção ambiental do Arquipélago para quatro quilômetros. Assim, mais uma vez, enfatiza-se a modificação da legislação para a viabilização do empreendimento, fundamentado na necessidade de gerar empregos.

Uma signifıcativa modificação também ocorreu no zoneamento industrial do município de Macaé paralelamente ao período de desenvolvimento dos estudos para a elaboração do EIA/RIMA da nova proposta do TEPOR.

As discussões em torno dessa mudança causaram polêmicas e divergências em vários aspectos e demonstraram a clara relação da mudança do zoneamento para atender à nova visão logística da reestruturação do empreendimento TEPOR, acarretando, inclusive, que o projeto de lei complementar ficasse conhecido como "Lei do Porto".

Juntamente com modificações nas zonas onde o porto e suas retroáreas se enquadravam, houve modificações em outras regiões da cidade e com uma área bastante superior à do projeto, como apresentado na Figura 4. 


\section{Figura 4 - Demarcação das zonas industriais de Macaé, conforme proposta na PL n. ${ }^{0}$ 013/2017, regulamentada pela LC $n .{ }^{0}$ 280/2018.}

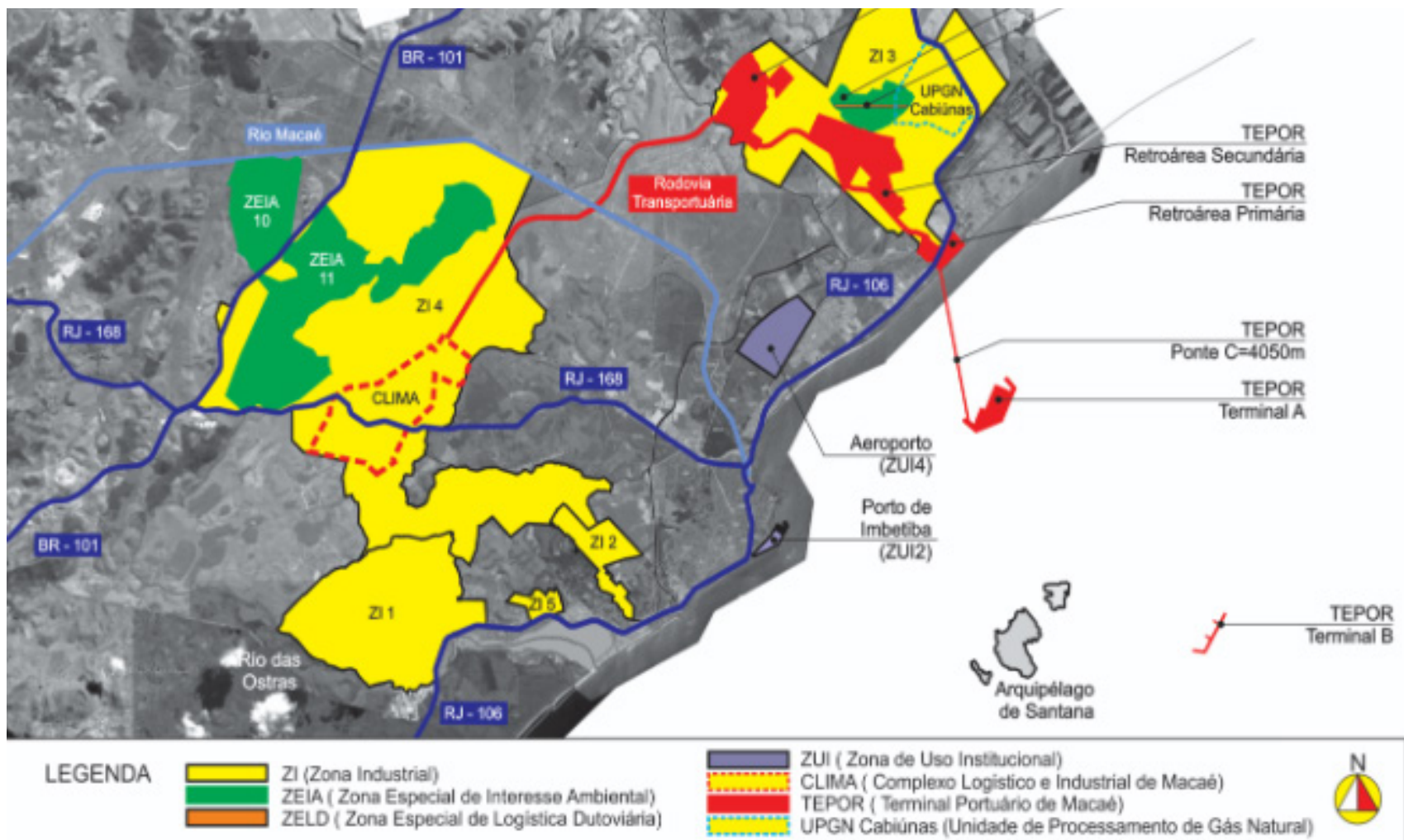

Fonte: Autoria própria, baseado no Código de Urbanismo de 2010 e LC 280/2018.

Uma das críticas das alterações da legislação foi que foi aprovada sem a apresentação do seu embasamento em análises e estudos técnicos, mesmo após inúmeras audiências públicas, sob o discurso de viabilizar a "logística do porto". Tal fato foi respaldado pela necessidade de atração de investimentos privados como solução no contexto de crise e desemprego.

Essa ampliação das áreas industriais de Macaé foi vislumbrada como uma alternativa de atuação como possível retroárea complementar ao porto. Assim, a Prefeitura de Macaé está construindo um anel viário, composto pelas rodovias Transportuária e Santa Tereza, que conecta as áreas industriais e o TEPOR.

Assim, verifıca-se que a "flexibilização" do planejamento urbano torna-se instrumento capaz de oferecer as condições necessárias para a atração e fixação do capital no território. 0 contexto competitivo entre cidades pela atração de investimentos acaba por contribuir para que esse tipo de situação aconteça, uma vez que o capital é fluido e seleciona lugares mais convenientes para investir.

Nesse sentido, com a crescente demanda por novos sistemas portuários no estado do Rio de Janeiro para atender à economia do petróleo, algumas cidades fluminenses têm vislumbrado, como oportunidade de alavancagem econômica, a instalação de "portosindústria", fomentando assim a disputa entre cidades e portos para a atração de investimentos. Entretanto, 0 contexto de descentralização das políticas públicas e de falta de planejamento e articulação política regional favorece o capital, que se beneficia com os incentivos fiscais, privilégios e facilitação para aprovação de empreendimentos que cada município oferece.

Também destaca-se, no atual contexto, a democratização dos processos decisórios no campo das políticas públicas de planejamento urbano como um significativo avanço proporcionado pelo Estatuto das Cidades, institucionalizando a participação da sociedade. Porém, observa-se que, a exemplo do caso do TEPOR em Macaé, cenários de crise, recessão e desemprego condicionam o convencimento da população em favor de empreendimentos privados que ganham status de "utilidade pública", legitimando, assim, a flexibilização do cumprimento de leis ambientais ou mesmo a modificação de leis.

Portanto, a reestruturação da legislação urbanística de zoneamento de Macaé, ampliando significativamente as zonas industriais sob o discurso de viabilizar a logística 
portuária, sinaliza a necessidade de se refletir sobre a aprovação de leis complementares de caráter específico e segmentado, em que se predomina o planejamento pontual sobre o da visão total da cidade, favorecendo que interesses privados passem a conduzir a política pública de planejamento urbano, sobrepondo-se aos interesses coletivos. Isso leva a concluir que o planejamento urbano municipal foi se moldando aos interesses econômicos, fomentado pelo empreendimento TEPOR, e que esse viés de "projeto de cidade", se não for revisto e amplamente debatido, irá contribuir ainda mais para perpetuar a fragmentação, a exclusão e o desrespeito às questões ambientais já vivenciados na cidade.

Nesse sentido, recorre-se a Jenks (HARVEY, 2006), ao relatar o risco da transição de mecanismos planejados para mecanismos imediatistas e de mercado, levando ao esvaziamento das políticas públicas de planejamento de longo prazo, legitimadas pela formação do consenso de retomada da economia que, como salientou Arantes (2000), nos mostra como a exploração do "cenário de crise" é propícia à ideologia da "geração de empregos" como motor de projetos.

\section{CONSIDERAÇÕES FINAIS}

As cidades portuárias caracterizam-se por abrigar um equipamento urbano que é, simultaneamente, infraestrutura local e parte integrante de redes de distribuição/circulação da produção em diferentes escalas, regional, nacional ou internacional (RIAL, 2008). Nesse contexto, Macaé tem, na presença histórica de seu porto, fator determinante para a consolidação dos seus ciclos principais de desenvolvimento econômico.
Assim, atualmente, a junção das indústrias de petróleo e gás, energia e portos consolidam Macaé no cenário global, e a cidade vai se adequando ainda mais à conjuntura do modo de produção capitalista, pautada na internacionalização do capital, uma vez que os portos são fundamentais no processo de organização do espaço econômico mundial, identificado como o aumento nas esferas de circulação e trocas compreendendo o aumento dos fluxos de mercadorias, pessoas, capital e informações (MONIÉ, 2003).

Nesse sentido, o empreendimento foi reestruturado para atender às necessidades de seus futuros possíveis clientes, principalmente petroleiras e prestadores de serviços estrangeiros, que, possibilitados pela abertura comercial que segue em curso também no País, buscam novos espaços para expandir seus mercados no cenário comercial globalizado.

Entre as dinâmicas das mudanças da mundialização, destaca-se, no contexto desta pesquisa, a atuação competitiva das instituições econômicas, devido, principalmente, à propagação da adoção de práticas neoliberais, como o livre comércio, e à difusão para outras organizações, inclusive no setor público das práticas, técnicas e instrumentos de gestão empresarial.

Assim, impulsionados por contextos de crise econômica, ideias e ferramentas gerenciais advindas do setor privado, passaram a ser assimilados pelo setor público sob o discurso de que, para "vencer" a recessão, tornou-se necessário o rompimento de um sistema considerado moroso, burocrático e ineficiente. Nesse sentido, prega-se a assimilação de novas formas de gestão, mais flexíveis e adaptáveis, para criar ambiente favorável e atrativo aos investidores externos, operando, dessa maneira, uma

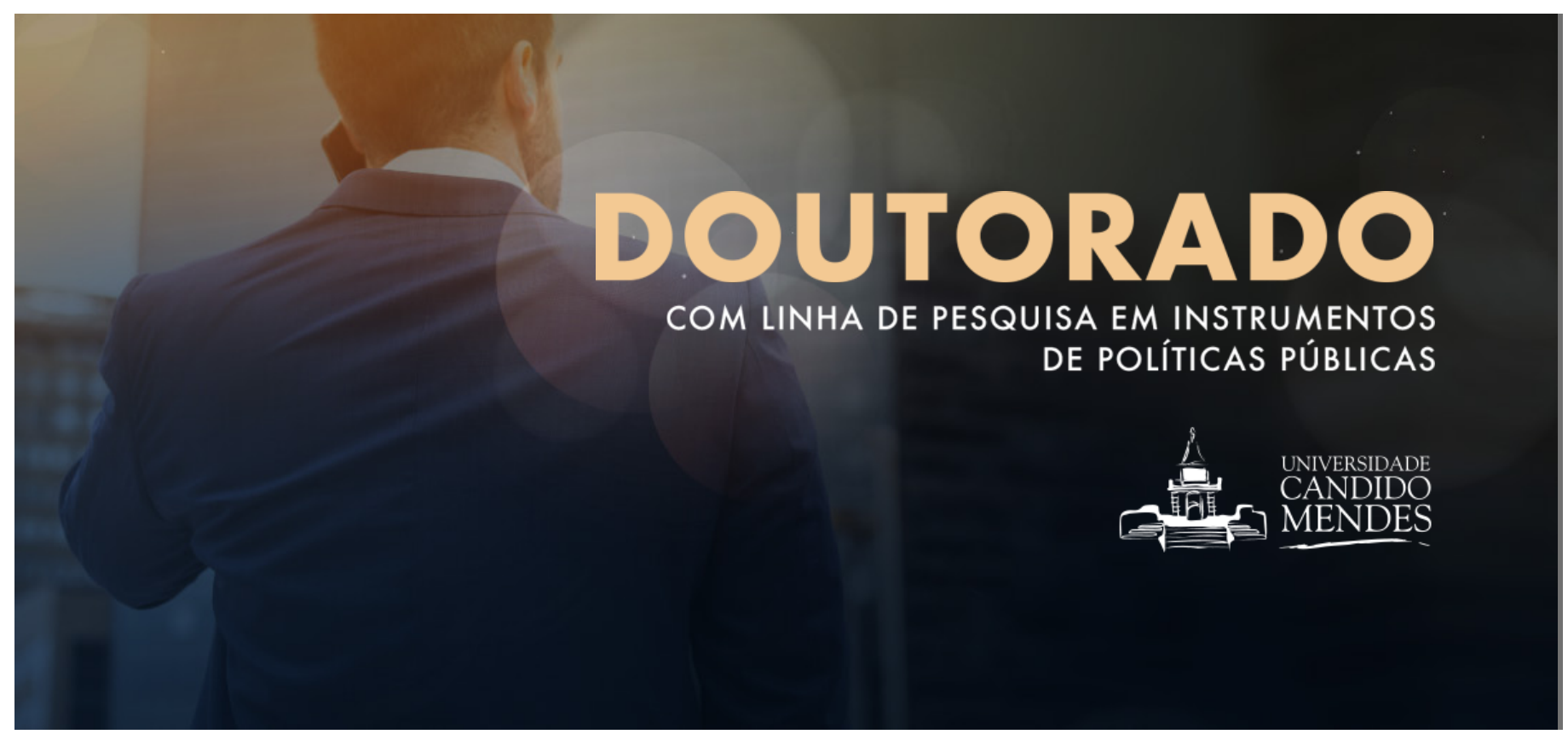


nova lógica na produção de espaços para acumulação do capital, fomentado e articulado pela iniciativa pública.

Neste sentido, perde centralidade o papel regulador historicamente exercido pelo Estado e recebe destaque o que Harvey (2006) define como processo de empreendedorismo urbano.

Dessa forma, o poder público de Macaé - enquanto cidade portuária na economia do petróleo, num contexto de significativa queda da produção da commodity na Bacia de Campos e consequente redirecionamento de investimentos para a Bacia de Santos - procura, mediante uma aproximação com a iniciativa privada, viabilizar a construção de um grande projeto portuário, logístico e industrial, o TEPOR, a fim de alavancar a atratividade de empresas, principalmente dos setores de energia e petroquímica para seu território.

Porém, a proximidade com o empreendimento portuário do Açu e a limitação de oferta deste serviço em Macaé, gerando a migração de empresas, contribuiu para acirrar ainda mais a disputa pela atração de investimentos deste ramo por cidades na região.

A abundância de recursos provenientes da economia do petróleo é finita, e o maior desafio deveria ser buscar a diversificação econômica. Entretanto, o poder público de Macaé objetiva transformar a cidade de "Capital Nacional do Petróleo" para "Polo Nacional de Produção de Energia". Sendo assim, o novo porto tem sido vislumbrado como um grande projeto de investimento privado capaz de induzir o crescimento econômico com a atração de demais indústrias ainda diretamente ligadas a essa commodity.

Entretanto, como um contraponto a ser debatido e melhor analisado em estudos futuros, a proposta de integração do TEPOR às demais áreas industriais da cidade pode, dependendo das conjunturas futuras, conferir ao empreendimento e à cidade, uma possibilidade de potencializar a atividade petrolífera, atuante com aproximadamente 40 anos de atividade no setor, espraiada no território municipal em locais historicamente já consolidados. Nesse sentido, essa interação levaria o empreendimento a assumir a cidade como uma grande retroárea industrial e de serviço já consolidada.

Esse planejamento das conexões das zonas industriais ao porto, se planejada com seriedade, poderia potencializar Macaé como uma cidade portuária, uma vez que demonstra a intenção de transformar o empreendimento portuário em "... um instrumento a serviço de um projeto de desenvolvimento" (MONIÉ e VIDAL, 2006), defendido pelo poder público municipal como "logística do porto".
Nesse sentido, ao tratar sobre a possibilidade de fixação de valor agregado quando a tradicional função de transporte portuário é superada, Monié (2011) destaca que a cidade portuária considerável é aquela que se distingue pela existência de um projeto incorporando o porto ao desenvolvimento urbano; pela mobilização dos atores locais voltada para a definição de políticas públicas integradas; por ações em prol do crescimento da atividade portuária; pela disponibilização de parte da área portuária; para o consumo da população e dos turistas; e finalmente, por uma participação expressiva do porto na geração de riqueza, emprego e trabalho.

Llovera (1999) também ressalta que a melhoria das relações porto-cidade, através de uma gestão compartilhada e que aproveite as condições favoráveis de ambos, potencializando os fatores de crescimento do porto, da cidade e da sua mais ampla hinterlândia, é uma alternativa para o desenvolvimento sustentável da cidade portuária.

Dessa maneira, enquanto cidade portuária, Macaé manteria, nas atividades de seu porto, um dos elementos básicos do desenvolvimento econômico. "Assim tem sido historicamente, e assim pode continuar a ser no futuro, se a cidade e seu porto souberem assumir as novas funções e as novas dinâmicas que a globalização econômica, a nova localização da produção, a integração econômica no nível continental, a organização dos transportes e a logística apresentam na atualidade" (LLOVERA, 1999:210).

Enfim, baseado em Monié (2011), o presente estudo conclui que é possível a consolidação de um novo "paradigma portuário" para Macaé ao se repensar a relação cidade, petróleo e gás e logística portuária de forma inovadora, transformando a plataforma portuária em ferramenta a serviço do desenvolvimento do território e da população local.

Entretanto, tendo em vista como as ações de políticas públicas de planejamento urbano vêm sendo pontualmente conduzidas, aparentemente desconsiderando análises técnicas que embasem o "projeto político" de cidade, hora proposto pelo executivo, a relação entre o porto e a cidade pode tornar-se progressivamente mais conflituosa. Esse fato pode se dar, principalmente, pela expansão industrial prevista como logística portuária, especialmente por estar relacionada a empreendimentos potencialmente poluidores e de risco que, com a aprovação da "Lei do Porto", permite-se que sejam implantados nas áreas industriais dispersas pela cidade, potencializando, assim, o possível afastamento da cidade ao complexo portuário. 
Desse modo, o poder público municipal precisa primeiramente considerar, nas suas políticas públicas de planejamento urbano, o tipo de relação que a cidade pretende estabelecer com o complexo portuário. Nessa perspectiva, o trabalho apresenta como alternativa a chamada "cidade portuária", que orienta a cidade a se relacionar de maneira mais integrada com o porto, oferecendo serviços complementares a este e aproveitando as atividades ligadas à atividade portuária como promotoras do desenvolvimento local (MEYER, 1999, in RIAL, 2008).

Contudo, a pesquisa identificou que o discurso da industrialização como motor das transformações da sociedade - que caracterizou o início da sociedade moderna - se faz presente até os dias atuais na emblemática sociedade contemporânea, embora com profundas transformações pautadas em um processo globalizante de financeirização do capital que atua sobre os territórios.

Ainda, diante do contexto de descentralização das políticas públicas e da falta de um planejamento e articulação política regional, inclusive no setor portuário onde se consolida a competição entre cidades para a atração de investimentos, os desdobramentos do processo de urbanização pautados em modelos de planejamento urbano de cunho empresarial seguem reproduzindo a lógica do capital, agora globalizado, justificado, na maioria das vezes, pela possibilidade de superar o contexto de crise.

Dessa forma, em Macaé, o estado tem se mostrado, também, agente reprodutor da lógica mercadológica do capital e modelador privilegiado do território através das políticas públicas urbanas. Semelhanças perceptíveis ao planejamento que Souza (2006) caracteriza como de facilitação, que atua estimulando a iniciativa privada, oferecendo-Ihe vantagens e abolição de restrições legais.

Nesse sentido, parece distante a idéia de que o poder público local elabore e execute um planejamento urbano em que cidade, porto e região busquem se potencializar mutuamente, pautado no objetivo de um desenvolvimento sustentável. Assim, infelizmente, nesse processo, não ficam evidenciadas possíveis externalidades positivas do projeto em relação a um planejamento e a uma gestão de longo prazo comprometidos com a melhoria da qualidade de vida e com o aumento da justiça social do entorno imediato ao TEPOR, nem da cidade em sua totalidade, nem por parte do empreendedor, nem do governo municipal. 


\section{Referências}

ARANTES, O., VAINER, C., MARICATO, E. A cidade do pensamento único. Desmanchando Consensos. Rio de Janeiro: Vozes, 2000.

BARBOZA, L; BRUST, C. Novo Porto: Câmara aprova doação de área para o projeto. 2011. Disponível em: www.macae.rj.gov.br. Acesso em: 04 de março de 2020.

CASTELLS, M. A questão urbana. Rio de Janeiro: Paz e Terra, 1983.

CASTElLS, M; BORJA, J. As Cidades como Atores Políticos. Novos Estudos, CEBRAP, n. 45, jul. 1996, p. 152-166.

HARVEY, D. Condição pós-moderna: uma pesquisa sobre as origens da mudança cultural. 15. ed. Tradução de Adail Ubirajara Sobral e Maria Stela Gonçalves. Rio de Janeiro: Edições Loyola, 2006.

LEFEBVRE, Henri. 0 Direito à Cidade. São Paulo: Centauro Editora, 2001.

LLOVERA, J. A. Por um desenvolvimento sustentável da cidade portuária. In COCCO, Giuseppe; SILVA, Gerardo (Orgs). Cidades e portos: os espaços da globalização. Rio de Janeiro: DP\&A, 1999.

MONIÉ, F. Globalização, modernização do sistema portuário e relações cidade; porto no Brasil. In: Silveira, M. R. (org): Geografia dos transportes, circulação e logística no Brasil. São Paulo: Outras expressões, 2011. p. 299-330.

MONIÉ, F. Análise Geopolítica dos Conflitos Territoriais na área de influência do Complexo Portuário e Industrial do Açu - São João da Barra, RJ.

Revista Cadernos de Desenvolvimento Fluminense, Rio de Janeiro, n. 9, p. 69-83, 2016.

MONIE, F., VASCONCELOS, F. Evolução das relações entre cidades e portos: entre logicas homogeneizantes e dinâmicas de diferenciação. Revista franco-brasileira de geografia, n. 15, 2012.

MONIE, F., VIDAL, S. Cidades, portos e cidades portuárias na era da integração produtiva. Revista de Administração pública, Rio de Janeiro, v. 40, n. 6, p. 975-995, 2006. Disponível em: https://www.scielo.br/scielo.php?pid=S0034-76122006000600003\&script=sci_abstract\&tIng=pt. Acesso em: 02 dez. 2019.

NADER, G. Os impactos da recente crise do setor de petróleo em Macaé. In: SILVA, S.; CARVALHO, M. (Org.). Macaé do Caos ao Conhecimento. Macaé: Prefeitura Municipal de Macaé, 2019, v. 1, p. 234-248.

PESSANHA, R. M. A relação transescalar e multidimensional "Petróleo-Porto" como produtora de novas territorialidades. Tese, UERJ, Rio de Janeiro, 2017.

PINTO JUNIOR, H. Q. et al. Economia da energia: fundamentos econômicos, evolução histórica e organização industrial. Rio de Janeiro: Elsevier, 2016.

RIAL, M. F. P. Cidade-porto: dinâmicas espaciais e planejamento intra-urbano. Dissertação (Mestrado), FAUUSP, São Paulo, 2008.

ROLNIK, R. Planejamento Urbano nos anos 90: novas perspectivas para velhos temas. In: RIBEIRO, L. C. de 0.; SANTOS JUNIOR, O. A. dos (org.). Globalização, fragmentação e Reforma Urbana - o futuro das cidades brasileiras na crise. Rio de Janeiro: Civilização Brasileira, 1994.

SANTOS, M. Por uma outra Globalização: do pensamento único a consciência universal. 3 ed. Ed. Record, 2000.

SOUZA, M. L. de. Cidades, globalização e determinismo econômico. Revista Cidades, [s.I.], v.3, n. 5, p. 123-142, 2006. 